\title{
A LINGUAGEM COMO INSTRUMENTO COGNITIVO NO TRABALHO DOS OPERADORES DE PROCESSO CONTÍNUO DE PRODUÇÃO
}

\section{THE LANGUAGE AS A COGNITIVE INSTRUMENT IN THE WORK OF OPERATORS OF THE CONTINUOUS PROCESS PRODUCTION}

\author{
Gilbert Cardoso Bouyer* E-mail: gilbertcb@uol.com.br \\ *Universidade Federal de Ouro Preto (UFOP), Campus João Monlevade - MG
}

\begin{abstract}
Resumo: Este artigo demonstra que há uma forte relação entre linguagem, cognição e percepção na atividade de trabalho de controle de processo contínuo. O método de pesquisa adotado foi a análise ergonômica do trabalho. Um grupo de 35 operadores de controle de processo contínuo foi estudado. Os resultados sugerem que expressões linguísticas e percepção evidenciam experiências corporais recorrentes, e mostram que a estrutura da linguagem que o operador habitualmente usa influencia o modo como ele percebe seu ambiente, e o modo como ele percebe seu ambiente influencia a estrutura da linguagem no trabalho. A linguagem não é meramente uma expressão do conhecimento adquirido pelo operador. Há uma correspondência fundamental entre pensamento, linguagem e percepção, de modo que um fornece recursos para o outro. Os significados básicos de termos do trabalho assim adquiridos serão embriões para a formação de conceitos importantes para a atividade de trabalho. Um operador inicialmente aparenta usar a linguagem para uma interação social superficial mas, a partir de certo ponto, esta linguagem penetra no subconsciente vindo a se constituir na estrutura do pensamento do operador no trabalho.
\end{abstract}

Palavras-chave: Cognição. Ergonomia. Linguagem.

Abstract: This article demonstrate that there is a strong relation between language, cognition and perception in the work activity of continuous process control. The method of research adopted was the ergonomic work analysis. A group made up of 35 operators of the continuous process control was studied. The results suggest that linguistic expressions and perception evidence recurrent body experiences, and show that the structure of the language that operator habitually uses influences the way he perceives his environment, and "way he perceives his environment" influences the structure of the language at work. Language is not merely an expression of the knowledge that the operator has acquired. There is a fundamental correspondence between thought, language and perception, in terms of one providing resources to the other. The basic work's term-meanings thus acquired will be the embryos of important concepts formation for the work activity. An operator first seems to use language for superficial social interaction, but at some point this language goes underground to become the structure of the operator's thinking at work.

Key-words: Cognition. Ergonomics. Language.

\section{INTRODUÇÃO}

Este trabalho resultou de uma pesquisa empírica, de dois anos, envolvendo 
35 operadores de controle de processo contínuo em indústrias de cimento, siderurgia e petroquímica. Foram estudadas 56 situações-problema ao todo, envolvendo a gestão de situações dinâmicas (HOC, 2004), conforme será explicado a seguir. Destas 56 situações dinâmicas, 19 foram coletadas e analisadas em duas empresas siderúrgicas; 28 numa fábrica de cimento e 9 numa refinaria de petróleo.

A questão da linguagem, na atividade de controle de processo contínuo, apresenta-se como um elemento de interesse do engenheiro de produção, no mesmo nível que outros elementos do sistema de produção também importantes para os objetivos de produtividade, qualidade e eficiência do processo. Isso se justifica pelo fato de ser a linguagem um instrumento de trabalho, na atividade dos operadores, que, em conjunto com os demais instrumentos, dispositivos, técnicas e métodos focados pelo engenheiro de produção em seu campo de atuação, mostrase indispensável para o alcance dos objetivos e metas da produção.

$\mathrm{Na}$ atividade de trabalho dos controladores (ou operadores) de indústrias de processo contínuo, a linguagem desempenha um papel fundamental. Ela funciona como um instrumento essencial para a eficiência desta atividade. Esta pesquisa detectou que os operadores utilizam-se de uma linguagem peculiar para agilizar as tomadas de decisão, diante de inúmeras situações, para reduzir o tempo da ação e para fazer intervenções mais precisas e seguras sobre o processo produtivo. Para os operadores manterem o processo produtivo dentro dos parâmetros esperados de normalidade, a sua linguagem é fundamental. Esta é a principal hipótese deste estudo.

Verifica-se que a eficiência no controle de processo contínuo de produção resulta não apenas da inovação tecnológica nos sistemas automatizados, mas da integração entre uma boa automatização e a competência dos trabalhadores humanos. A autonomia dos operadores não deve ser limitada diante dos novos sistemas, e sim integrada com os recursos tecnológicos para um melhor curso da ação de controle.

Não se trata de contrapor automatização e competência / experiência dos operadores, mas de afirmar que a integração entre ambas é necessária para o bom desempenho almejado desde o projeto dos engenheiros.

Um sistema automatizado de controle de processo contínuo é um sistema do 
tipo SDCD (Sistema Digital de Controle Distribuído). Este tipo de sistema é uma interface entre os operadores (que controlam o processo de produção) e o processo produtivo. Os operadores controlam o processo por intermédio do SDCD, que possui sensores, dispositivos de controle, circuitos e válvulas que permitem, pelas telas, teclado e mouse, supervisionar o estado do processo (temperatura, pressão, entradas de matérias-primas, saída de produtos acabados, etc.) e intervir sobre ele. Embora os operadores fiquem fixos numa sala de controle, equipada com ar condicionado, boa iluminação e computadores sofisticados (sob seu controle), eles podem controlar toda a planta industrial, e praticamente todo o processo de produção pelo SDCD.

A modernização dos sistemas de produção, nos últimos quinze anos, pela introdução dos sistemas automatizados de controle de processo, aparece como uma das condições de sobrevivência das IPC's (Indústrias de Processo Contínuo). As indústrias têm, então, buscado utilizar sistemas de controle com desempenho cada vez melhor, o que impacta significativamente no trabalho dos operadores (THIBAULT, 2002).

No controle do processo contínuo, a linguagem desempenha um papel fundamental. Por meio dela, ocorre a planificação da ação e a elaboração de um modelo operativo sobre o estado do processo produtivo. O modelo operativo é uma construção mental, uma interface entre o estado real da situação e a ação do operador (PASTRÉ, 2005). Ele permite a realização de deduções sobre o processo de produção e funciona como uma construção mental capaz de suprir as lacunas deixadas pela falta de informação necessária ao controle de processo. A linguagem permite ao operador obter informações sobre o estado do processo (a partir do coletivo de trabalho), alimentando seu modelo operativo, para daí formular suas hipóteses sobre o estado do processo, checar suas percepções junto aos demais trabalhadores da área de produção e comunicar as intervenções realizadas para, posteriormente, obter novas informações sobre os efeitos de suas ações e assim sucessivamente. Neste círculo de ação-linguagem é que o processo pode ser mantido dentro dos parâmetros esperados de normalidade.

Esta manutenção do processo dentro dos parâmetros de normalidade resulta de uma atividade instrumental ou atividade mediatisada (FOLCHER; RABARDEL, 
2004). Ou seja, o operador se vale de linguagem, artefatos, esquemas de utilização e instrumentos cognitivos, enquanto recursos internos adquiridos e desenvolvidos numa história de pertença a uma dada cultura do processo de produção (apropriação de instrumentos culturais). Estes recursos internos são utilizados para transformar os recursos externos (tarefas), de modo a agir com eficiência. A noção de atividade mediatisada implica num modelo de homem como um sujeito socialmente situado, portador de significações e herdeiro de uma cultura singular do processo de produção em questão. Entretanto, o modelo de homem que serve de base para a concepção dos sistemas automatizados geralmente enxerga o ser humano como um processador de símbolos e informações, descontextualizado e não situado socialmente. Este equívoco tem resultado no projeto de sistemas que produzem severas dificuldades cognitivas à ação dos operadores, uma vez que a sua cognição é situada, cultural e socialmente.

Este trabalho verificou que a experiência do operador lhe permite adquirir um padrão de linguagem que é extremamente eficaz na resolução de problemas, em conjunto com outros trabalhadores da produção. Este padrão de linguagem permite a intercompreensão (ZARIFIAN, 1999) - compreensão mútua e recíproca - com os demais atores do processo produtivo, o que leva a uma eficiência de controle de processo materializada no equilíbrio que é mantido sobre as variáveis do processo de produção (temperatura, pressão, propriedades químicas dos produtos, etc). Importante destacar que essa intercompreensão é função da pertença a um mesmo domínio de atuação (operação/execução), sendo possível apenas entre os atores que se mantêm incorporados à materialidade concreta da produção. Assim, é rara a intercompreensão entre atores do domínio de atuação operação/execução do trabalho com os atores situados no outro domínio de atuação (concepção/projeto/planejamento do trabalho), como os engenheiros, informáticos e projetistas. Estes últimos não se encontram incorporados na atividade concreta de controle do processo (contato direto com equipamentos, matérias-primas, indicadores informais do estado do processo, etc.). Logo, não compartilham dos mesmos instrumentos cognitivos e da mesma linguagem dos operadores de processo e dos trabalhadores da área (aqueles que ficam no "chão-de-fábrica", exercendo tarefas de contato direto com os equipamentos e materiais). Há, portanto, 
uma fratura, um lapso, uma lacuna de comunicação entre engenheiros e operadores.

Este estudo identificou haver uma linguagem atrelada a uma forma de agir própria, ou atividade subjetivante (DEJOURS, 1997) que se define como um saber do corpo e como uma atividade repleta de habilidades e saberes tácitos, pautada por uma inteligência astuciosa ("métis") de difícil simbolização e comunicação aos demais atores. A linguagem que espelha esta atividade subjetivante é o que permite a intercompreensão e a ação eficaz em diversas situações. Detectamos ainda que estas aquisições, quer sejam compreendidas como habilidades, competências ou poderes de agir (RABARDEL, 2005), possuem suas raízes na história de experiência concreta de contato corporal com a área de produção, ainda que a atividade atual de controle do processo contínuo aparente ser essencialmente abstrata e cognitiva.

Trata-se de uma linguagem diferente daquela utilizada pelos engenheiros. $\mathrm{Na}$ linguagem dos operadores, temos elementos que somente são vivenciados no seu real do trabalho. Ou, como nos diz DEJOURS (1999), a palavra do agente sobre seu comportamento no trabalho é muito problemática e pode ser difícil para ele explicar e justificar seus atos. Segundo o autor, no trabalho existem muitas coisas que nem os operários nem os estudiosos sabem dizer. E, mais adiante, arremata o seu raciocínio, dizendo que "nossa linguagem sobre o trabalho é uma linguagem de engenheiros, inapta para descrever o real do trabalho" (DEJOURS, 1999, p. 66).

A linguagem verificada no trabalho dos operadores de processo contínuo está sempre em funcionamento, produzindo soluções e sanando os desvios que não são contemplados pela linguagem típica do trabalho prescrito na tarefa. Grande parcela desta linguagem permanece sem uma codificação simbólica reconhecida pelos engenheiros, gestores e projetistas dos sistemas, das tarefas e do trabalho (não há apostilas, livros, manuais, etc., que contenham e/ou traduzam a linguagem dos operadores e os saberes tácitos que ela reflete). Ainda que, na atualidade, esteja em voga a tentativa de objetivar e sistematizar o conhecimento tácito e os saberes dos operadores (como proposta da Engenharia do Conhecimento), eles permanecem um tanto quanto na clandestinidade. O conhecimento e a linguagem do trabalho prescrito (de projeto e concepção dos sistemas), dos engenheiros e projetistas, embora possam ser encontrados nos livros, apostilas, manuais, normas, etc., não 
abrangem a inesgotável amplitude da linguagem dos operadores e de seus saberes tácitos mobilizados na sua atividade. Muito da eficiência e da eficácia das tecnologias e dispositivos microeletrônicos empregados na produção contínua (sistemas especialistas e sistemas supervisórios) funcionam por conta do saber tácito (incorporado), das habilidades tácitas (DEJOURS, 1997) e da linguagem própria dos operadores.

Devido a esta barreira na linguagem, torna-se difícil a compreensão recíproca (intercompreensão) entre atores situados em diferentes domínios de atuação. Ou seja, temos, no processo estudado, dois domínios de atuação distintos, descritos por este autor, aqui tomados para análise: 1) o domínio de atuação dos engenheiros, gestores, informáticos e projetistas (domínio de atuação concepção/projeto/planejamento do trabalho); e 2) o domínio de atuação dos operadores e trabalhadores da área (domínio de atuação operação/execução do trabalho). A linguagem dos primeiros pode ser traduzida em termos simbólicos, em códigos e conhecimentos da engenharia e da informática, explícitos e já legitimados epistemologicamente segundo as leis da física, da química, da matemática, etc. Trata-se de um conhecimento formal e já objetivado, que os engenheiros e demais atores deste domínio utilizam para compreender e agir sobre o processo de produção. Por outro lado, temos a linguagem dos operadores, que reflete um saber tácito, uma inteligência astuciosa, uma "atividade subjetivante" ("subjektvierendes handeln") e a "métis" (DEJOURS, 1997), que se antecipam a qualquer simbolização, e que não desfrutam de uma objetivação, nem de uma formalização, como a linguagem dos engenheiros e gestores. Este segundo domínio de atuação possui a sua própria linguagem que, embora rica e essencial ao controle do processo, não é reconhecida sendo, até mesmo, desconhecida.

A linguagem, como instrumento de trabalho, não abarca toda a amplitude daquilo que Bationo-Tillon, Folcher e Rabardel (2010) denominam de atividade narrativa, ou "atividade produtiva diacrônica" - ("activité productive diachronique") intimamente ligada a uma atividade criativa que não se explicita completamente no curso da ação. A atividade narrativa não se enquadra numa prescrição e não pode ser predefinida de antemão, segundo estes autores. Como exemplo de atividade narrativa, apresenta-se o trabalho do arquiteto, em que o desenho que aparece no 
papel, sua forma de se expressar no mundo, "narra" muito pouco do seu processo cognitivo criativo (ou como dizem esses autores, o que está em "sua cabeça" (pág. 64), e que não se explicita integralmente em sua comunicação) (Bationo-Tillon, Folcher e Rabardel, 2010). A atividade narrativa se inscreve num tempo longo. Tem este nome porque ela se orienta para a realização de uma tarefa de longo curso, que engloba toda uma narrativa de sua temporalidade. No caso dos operadores de processo contínuo, essa atividade demanda a linguagem para a sua concretização na forma de alterações precisas e seguras sobre o processo (diferente do exemplo do arquiteto de Rabardel, cuja atividade demanda o lápis e o papel...).

Para alguns autores da Ergonomia Cognitiva, em atividade de trabalho, a ação incorporada é a base sobre a qual se instalam a linguagem e a cognição (BOUYER, 2008). A ação cria um mundo peculiar que aloja, em seu interior, a linguagem que os atores nele situado compartilham. E esta linguagem, como também encontrado no presente estudo, possui raízes no universo mais concreto e mundano da atividade de trabalho. Mas este mundo comum, de linguagem e cognição incorporadas, permanece invisível ao olhar dos observadores, ou seja, um tanto quanto clandestino, ainda que repleto de saberes e habilidades tácitas.

A linguagem e os saberes tácitos dos operadores, portanto, operam numa espécie de clandestinidade perante os outros atores do processo produtivo, suprindo o distanciamento entre o trabalho prescrito e o trabalho real. A compreensão recíproca ou intercompreensão torna-se possível somente entre trabalhadores situados num mesmo domínio de atuação ou "mundo comum" (PASTRÉ, 2005, p. 248-249), ou seja, atores que compartilham de uma mesma linguagem, conforme será explicado mais adiante. Isso implica que a racionalidade e o sentido da ação são funções da pertença a um mesmo mundo comum, a um mesmo domínio de atuação. Uma ação de um operador é reconhecida e validada como útil por um companheiro de trabalho que pertença ao seu mundo de atuação, mas apresenta-se sem sentido para um engenheiro situado em outro domínio de atuação, e vice-versa. O domínio de atuação de um engenheiro é aquele da prescrição, do planejamento e concepção do trabalho, na forma de tarefas ou planos de ação pautados por conhecimentos formalizados e legitimados pela comunidade científica. O domínio de atuação de um operador é aquele da execução das tarefas, porém, uma execução 
que se apóia num saber tácito não objetivado e não formalizado, que singulariza a tarefa (prescrição) determinada pelos projetistas do trabalho (engenheiros). Para singularizar o trabalho prescrito, é preciso se valer do trabalho real (DEJOURS, 1997, p. 40-41), o qual, muitas vezes, implica, segundo este autor, em descumprir as próprias normas prescritas para poder agir de forma eficaz.

Esse distanciamento de mundos distintos de atividade cognitiva e linguagem, inseridos em contextos distintos de ação, foi detectado por alguns autores da ergonomia cognitiva (BOUYER; SZNELWAR, 2007), os quais chegam mesmo a postular a existência de uma lacuna ontológica que separa a cognição e a linguagem dos atores situados em contextos de ação distintos um do outro.

\section{PROBLEMA DE PESQUISA E HIPÓTESES}

A linguagem como "ferramenta" (instrumento, no sentido dado a este termo pela psicologia social) de trabalho. Eis o presente problema de pesquisa. Qual o papel que a linguagem exerce na atividade de trabalho dos operadores de processo contínuo?

A hipótese de pesquisa deste estudo é que, no que diz respeito à linguagem utilizada como instrumento no controle de processo contínuo: 1) ela permite um intercâmbio, uma intercompreensão, na dimensão comunicacional, entre os atores do processo produtivo situados num mesmo domínio de atuação (operação/execução). 2) Ela é essencial para a manutenção do processo dentro dos parâmetros esperados de normalidade. 3) Ela resulta de uma vivência histórica no interior de um determinado processo produtivo, atrelada a experiências corporais de contato com a materialidade deste processo. 3) Ela está associada a uma percepção peculiar, uma percepção compartilhada por alguns atores da produção, e não compartilhada por outros atores de outros domínios de atuação.

Ou seja, operadores de controle de processo contínuo e operadores da área (chão-de-fábrica) possuem percepções similares quanto aos indicadores indiretos do processo produtivo, mas esta percepção, por eles compartilhada, é diferente da percepção de outros atores, situados em outro domínio de atuação, como supervisores, gestores, engenheiros, etc. 
A hipótese afirma, então, que a linguagem compartilhada entre operadores e trabalhadores de área permite, a este coletivo, controlar o processo produtivo com eficiência. Essa linguagem comum resulta de uma longa história de vivência junto a um dado processo de produção. E, além disso, essa linguagem espelha ou reflete uma forma de percepção peculiar compartilhada apenas por atores envolvidos na materialidade concreta do processo de produção.

Esta hipótese pode ser comprovada pela análise do discurso dos operadores e pelas situações de controle do processo de produção. Por exemplo, nas indústrias siderúrgicas pesquisadas, o coletivo formado por operadores e trabalhadores de área consegue classificar e qualificar o andamento do processo produtivo (se está sob controle, se apresenta alguma anormalidade, etc.) pelas características da fumaça que sai do forno. Verificou-se que os operadores e trabalhadores de área (forneiro, lingoteiro, dangueiro) conseguem atribuir, em sua linguagem, diferentes adjetivos para a fumaça que sai do forno. Estes adjetivos espelham a sua percepção apurada sobre o processamento químico do minério. Por exemplo, eles dizem que a fumaça às vezes está "limpa", "suja”, "clara”, "escura”, "leve”, "pesada”, "encorpada”, "rala", etc.

Cada um desses termos corresponde a sua percepção da fumaça e a uma correlação com o estado do processo que ocorre no interior do forno. Interessante notar que os demais atores menos envolvidos materialmente com a área de produção (como gestores e engenheiros) não conseguem distinguir uma fumaça da outra e nem compreender o que significa uma fumaça "leve", ou "pesada" ou "limpa", "suja", etc.

"Fumaça é fumaça, é tudo igual, o controle do processo não pode ser baseado na fumaça e sim nos parâmetros do sistema especialista" (depoimento de um engenheiro de processo).

"Olha, se eu não ver a fumaça, fico perdido. Ela varia muito durante o dia de trabalho. É olhando ela que eu sei como está o processo" (operador de processo contínuo).

As percepções do engenheiro e do operador são distintas porque eles possuem histórias profissionais, formações, aprendizagens e experiências distintas.

O operador, ao longo de sua história profissional, não adquiriu uma formação 
teórica para operar o processo, mas sim uma formação prática, resultante da experiência concreta sobre os equipamentos e matérias-primas. Esta aprendizagem, baseada na experiência física, permitiu a aquisição de esquemas perceptivos e de utilização (VERGNAUD, 1985; PASTRÉ, 2005; RABARDEL, 2005) que são amplamente utilizados no controle do processo. Os esquemas de utilização são definidos, por estes autores, como organizadores internos da ação. Eles, juntamente com os artefatos, compõem os instrumentos cognitivos.

O sistema perceptivo do operador encontra-se atrelado ao seu sistema sensório-motor. Foi agindo sobre o processo que ele adquiriu estruturas cognitivas de percepção que o engenheiro não possui. A percepção é, então, função da incorporação do agente ao cenário concreto da atividade de trabalho. A percepção não é um processo passivo de captação de sinais e processamento dos mesmos. Trata-se de um processo ativo em que o movimento, a ação, a atuação do operador (seu agir concreto sobre o seu domínio de atuação ou mundo comum) desempenham um papel determinante sobre aquilo que é percebido e como é percebido.

\section{A LINGUAGEM NO MUNDO CRIADO PELA ATIVIDADE DE TRABALHO}

A linguagem se insere num mundo peculiar da atividade de trabalho, que aqui pode ser compreendido pela noção de gênero de Clot (2004). Entendemos o gênero, conforme os estudos deste autor, como um "background" composto de instrumentos, saberes e regras tácitas, encontrados num coletivo de trabalho, que orientam e amparam a ação dos atores da atividade. O coletivo, segundo a noção de gênero, não é apenas a soma de indivíduos. O gênero se interpõe entre a ação individual e o coletivo de trabalho, pelos instrumentos, saberes, competências, estratégias e compromissos cognitivos, coletivamente cristalizados por uma história em uma atividade de trabalho específica. É por ele que cada trabalhador encontra apoio nos momentos de ação (incluindo as decisões). Portanto, o coletivo e o gênero têm o poder de proteger o sujeito até de si mesmo; poder de amparar as ações. O gênero engloba a "métis" ou inteligência e arte do ofício. Uma linguagem comum, ora estudada neste trabalho de pesquisa, está inserida no interior do gênero e atrelada à 
"métis".

Os trabalhadores compartilham de um mundo comum (PASTRÉ, 2005). Este mundo comum agrega os agentes de habilidades incorporadas (tácitas) que efetuam um intercâmbio na linguagem, mas isola-os dos demais agentes de outros "mundos comuns...", nada comuns uns aos outros - ou domínios de atuações distintos (conforme explicado anteriormente: p.ex., o domínio de atuação planejamento/concepção e o domínio de atuação operação/execução). Trata-se, então, de mundos comuns distintos. Domínio de atuação e mundo comum, aqui, podem ser tomados como sinônimos.

Por exemplo, detectamos, pelos dados empíricos, que os engenheiros e projetistas possuem uma linguagem peculiar que é bastante distinta da linguagem dos operadores. Ou seja, cada qual em seu mundo compartilha, com os outros atores aí situados, de uma linguagem específica que reflete os saberes, regras tácitas, instrumentos cognitivos e vivências subjetivas enclausuradas em seu mundo comum. O intercâmbio entre os diferentes mundos de ação e linguagem se mostra difícil nas situações reais da atividade de trabalho.

As situações dinâmicas se caracterizam pelas possibilidades limitadas de controle por parte dos operadores - ou "controle parcial", conforme Hoc (2004). Lidar com situações dinâmicas requer mecanismos de adaptação - um conceito recorrente na ergonomia cognitiva - o qual reflete em mecanismos de regulação (conceito também bastante conhecido dos ergonomistas, descrito, por exemplo, em Guérin et al. (2002, p. 66) necessários para a gestão da variabilidade e da complexidade inerentes às situações dinâmicas.

A supervisão e o controle de um processo complexo (aquele que é pautado pelas situações dinâmicas), dentro dos parâmetros de normalidade, não provém do sistema automatizado e de suas regras, nem tampouco das regras explícitas encontradas no próprio sistema e no trabalho prescrito aos operadores. $\mathrm{O}$ ajuste fino (articulando as demandas da situação dinâmica e a ação do operador, para arcar com tal situação) e as regulações, necessárias à manutenção do sistema em conformidade com os objetivos predefinidos, resultam da intensa atividade cognitiva dos operadores.

Embora nos processos de trabalho contemporâneos estudados não ocorra 
uma ruptura com o clássico modelo de segregação entre concepção e execução, o domínio de atuação dos que executam o trabalho permanece repleto de habilidades, saberes, códigos e de uma linguagem, que lhes são bastante peculiares (SCHWARTZ, 1998, p. 124) e invisíveis ao olhar do observador de outros domínios de atuação ou outros mundos comuns (PASTRÉ, 2005, p. 248-249). Engenheiros, projetistas, gestores, informáticos e tecnólogos, responsáveis pelo projeto dos sistemas (domínio de concepção) não partilham e não estão em comunhão com a linguagem dos operadores (domínio de execução). E vice-versa. É como se estivessem em mundos distintos: um mundo dos conceptores e um mundo dos trabalhadores (operadores) - que aqui denominamos de domínios de atuação distintos (ou mundo comum): o domínio de atuação planejamento-concepção e o domínio de atuação execução-operação. Concebe-se um sistema sem conhecer, de perto, as formas de atuação dos operadores. Isso impõe severas dificuldades à atividade mental de controle do processo: a falta de informações no sistema e a necessidade de se valer de fontes secundárias de informações (não previstas no projeto) é um exemplo de uma dessas dificuldades. Um outro exemplo é a inclusão, no sistema, de regras que não ganham sentido na atividade dos operadores, levando-os a desviar ou mesmo desativar determinadas funções do sistema automatizado.

As habilidades tácitas, incorporadas (provenientes das experiências corporais), compõem aquilo que Dejours (1997, p. 43-44) denomina de inteligência do corpo. A importância dessas habilidades incorporadas, intangíveis por uma análise superficial da atividade de trabalho, torna-se nítida pelo fato de serem essenciais para o operador enfrentar eventos (acontecimentos imprevistos da produção, conforme explicado por Zarifian (1999) em seus estudos), panes, incidentes, etc. Essas habilidades não são explicitadas, formalizadas ou sequer explicadas pelo domínio simbólico formalizável (SCHWARTZ, 1998, p. 122) dos engenheiros e projetistas dos sistemas. Não há como simbolizar inteiramente a parcela do real que escapa de qualquer simbolização (DEJOURS, 1997), e isso vale tanto para as situações não inteiramente antecipáveis (situações dinâmicas, segundo definição de Hoc (2004)), quanto para o que é mobilizado no campo de atuação do operador: as suas habilidades tácitas atreladas ao corpo em atividade. 
A abordagem de mundo comum permite tratar do real do trabalho (DEJOURS, 1997) enquanto espaço de constituição da objetividade, pelo conhecimento aprofundado da atividade dos operadores. Trata-se de uma abordagem epistemológica que busca estudar as condições de constituição da objetividade. Isto que ela sublinha : nas relações que um sujeito estabelece com o real, é necessário voltar uma atenção extrema ao mundo comum no qual ele se insere (PASTRÉ, 2005, p. 248).

Mas se a prescrição taylorista, atualmente, tende a ceder terreno a uma prescrição subjetiva e cognitiva (CLOT, 1995), mais se faz necessária a relação do sujeito com o saber e mais grave se torna a premência das habilidades incorporadas no processo de trabalho. A gestão da atividade cognitiva envolve parte de um saber que não pode ser gerido externamente e, apenas por uma racionalidade limitada, ele pode ser governado.

\section{MÉTODOS DE PESQUISA}

O material empírico essencial deste trabalho de pesquisa é constituído pelo discurso dos 35 operadores estudados, em indústrias de siderurgia, cimento e petroquímica. As falas ou verbalizações dos operadores do processo contínuo formaram o substrato primordial para as análises desta pesquisa. Ainda que aparente se tratar de frases ou enunciados soltos, ou aparentemente isolados de um contexto, eles guardam íntima relação com as situações específicas de trabalho e com os contextos da atividade de trabalho estudados. Não foi apenas o contexto, não foram apenas as condições de contorno da situação e não foram somente as variáveis do processo os objetos de análise desta pesquisa. $\mathrm{O}$ objeto de análise, neste estudo, foi, fundamental e essencialmente, a fala do trabalhador.

$\mathrm{Na}$ fala, por meio da fala, a hipótese de pesquisa ora formulada pôde ser investigada. Ainda que as situações carreguem consigo os aspectos de um ambiente de engenharia, ou resquícios das técnicas e processos de produção, não foram os aspectos técnicos do processo e da engenharia os objetos de análise, mas sim os aspectos humanos, históricos, ontogenéticos e sócio-históricos que se manifestam nas falas dos operadores. Suas modificações interiores (ontogenéticas, 
de aquisição de esquemas e de potencialidades de agir), que refletem em sua linguagem peculiar, foram o objeto central deste estudo.

A análise do discurso buscou averiguar como os indicadores indiretos eram, pelos operadores, correlacionados com o comportamento de curvas e parâmetros de telas e como eram utilizados para apreender suas significações no cenário da produção. Essa capacidade de dedução e de inferência revelou-se fruto, conforme mostrou o discurso dos operadores, qualquer que fosse o contexto, de uma vivência histórica do processo de produção, com suas inúmeras situações eventuais.

De acordo com a Análise Ergonômica do Trabalho /AET (WISNER, 1987), o discurso dos trabalhadores a respeito da atividade de trabalho deve ser mediado pelas características objetivas das ações inseridas na atividade (trabalho real). Sendo uma grande parte da atividade inacessível pela observação unicamente do comportamento visível (HUBAULT, 2004), unicamente a observação exterior e sistemática desses comportamentos visíveis não possibilita um acesso às estratégias mentais, esquemas de utilização e modelos do operador. Assim, a AET veio a contribuir de modo a fornecer possibilidades de objetivação do que se mostrava subjetivo no trabalho, como saberes tácitos e percepções singulares. Foi preciso, então, aprofundar nas verbalizações dos operadores incitadas pelos métodos familiares à análise ergonômica do trabalho (GUÉRIN et al., 2002).

$\mathrm{Na}$ coleta das verbalizações, em AET, é recomendável manter o verbo no presente e remeter o sujeito ao seu próprio comportamento, de acordo com aquilo que fora observado. As filmagens e gravações de entrevistas foram primordiais para a consolidação destes dados. Elas foram utilizadas também nas entrevistas. Questões do tipo "o que você está fazendo na...?"; "como você sabe que...?"; "quando é que você auxilia ... o que faz você decidir por esta intervenção...?"; "é sempre assim ?"; "o que o leva a ... ?"; "o que o atrapalha...?", etc., foram largamente empregadas, conforme métodos de verbalizações propostos por Guérin et al. (2002).

O contexto impera nesta fase da pesquisa. A objetividade, a reconstituição minuciosa das situações, as observações sistemáticas juntam-se e buscam conduzir as falas, o discurso, culminando em momentos graves de confrontação daquilo que se diz com aquilo que se observa e que se tem, concretamente, numa situação real contextualizada. 
Após a coleta das falas e imagens, os operadores eram confrontados com as mesmas, e as novas verbalizações eram coletadas e novamente analisadas e discutidas com os mesmos, ao que em ergonomia recebem os nomes de autoconfrontação e autoconfrontações cruzadas (CLOT, 1995, p. 26).

No presente trabalho, foi necessário explorar mais ainda o discurso dos operadores, no domínio de suas experiências vividas em atividade de trabalho. As experiências vividas no trabalho são aquelas que não descartam as componentes mais subjetivas da ação, como os aspectos psíquicos, as sensações e as percepções. Essas componentes interagem e afetam as componentes cognitivas e, conseqüentemente, os resultados da ação (desempenho, eficiência).

Em suma, os métodos e técnicas de verbalizações da AET foram readaptados, em alguns momentos, tornando-se uma espécie de análise das verbalizações fornecidas sobre o que era vivido em situações nas quais os próprios atores (operadores, trabalhadores) julgavam ter marcado a sua história no controle do processo contínuo. Obviamente, a expressão "ter marcado" remete os métodos da pesquisa ao campo das subjetividades dos operadores, incluindo, aí, a análise da atividade subjetivante ou inteligência astuciosa descrita por Dejours (1997, p. 43-46), conforme anteriormente explicado.

\section{RESULTADOS E DISCUSSÕES}

Foram estudadas, conforme dito anteriormente, ao todo, 56 situaçõesproblema, sendo $19 \mathrm{em}$ duas empresas siderúrgicas, 28 numa fábrica de cimento $\mathrm{e}$ 9 numa refinaria de petróleo. 35 operadores destas empresas foram tomados para estudo. $O$ objetivo era averiguar o papel da linguagem informal (e das percepções peculiares correlatas) na resolução de problemas no processo produtivo, em destaque para a gestão de situações dinâmicas.

Constatamos que a maioria das situações-problema somente é resolvida por intermédio de uma linguagem informal, a qual é compartilhada somente pelos operadores e pelos trabalhadores da área que lidam diretamente com as matériasprimas e com os produtos imediatos do processo produtivo. Trata-se dos atores que possuem uma história comum no interior de um dado processo de produção. Por 
exemplo, na fábrica de cimento, das 28 situações-problema que tomamos para estudo, 27 foram resolvidas pelo uso de uma linguagem informal que reflete uma percepção peculiar, exclusiva dos operadores e do pessoal de área. Neste estudo, também constatamos que os engenheiros e demais atores do processo de produção permanecem alheios à linguagem e à percepção dos operadores, não conseguindo estabelecer uma intercompreensão com estes. Os dados constam nos Quadros 1 e 2.

No discurso dos operadores da IPC, independente de qual fosse o contexto, mostraram-se abundantes as expressões de referência histórica:

“desde... - antigamente - naquela época - nos tempos do painel lá de baixo - forno satélite - o outro forno - placas antigas - o outro sistema antes da expansão - depois da troca - a válvula antiga - a bomba que tinha lá - quando a gente trabalhava lá embaixo - tinha vez que - o fluxo era menor - a gente controlava só o forno - não tinha pré-calcinador"

Nas comunicações realizadas com a área de produção, os procedimentos de pesquisa buscaram avaliar a utilização de termos que remetiam à história de incorporação ao processo produtivo, os quais revelaram um saber tácito sobre os equipamentos e suas características e as matérias primas, ao longo do tempo. Isso ocorria qualquer que fosse o contexto da situação.

Daí, não houve uma excessiva preocupação em descrever aqui o contexto de cada situação, visto tratar-se de um traço característico de toda e qualquer situação investigada. A prova disso está dada na intensidade com que os operadores, incorporados no contexto do processo (e mais eficientes), utilizam-se dos indicadores indiretos. Estes surgem registrados em seu discurso, o qual revela, pelas análises efetuadas segundo rigorosos procedimentos de entrevista, a presença de imagens metafóricas e de esquemas-imagéticos para ação eficiente sobre o sistema.

Aspectos de uma poeira, sua quantidade no interior do forno, distribuição do material sobre a grelha, finura do material, presença de "rio vermelho" (camada de material incandescente), etc., surgiram no discurso e não demandaram a descrição detalhada de cada situação: o principal era a fala, qualquer que fosse a situação ou contexto. Esses esquemas-imagem mostraram, em todas as situações estudadas, 
uma relação direta com os termos de referência histórica e com os indicadores indiretos utilizados pelos operadores. Por isso, não houve a preocupação de relatar, em minúcias situacionais e contextuais, uma única situação específica, dado o caráter genérico e recorrente do fenômeno em estudo.

Em cada um dos quatro processos de produção estudados (produção de cimento, produção siderúrgica (duas empresas) e refino de petróleo) foram identificados, na linguagem dos operadores com o pessoal de área, parâmetros informais percebidos em etapas específicas do processo, e utilizados no controle do mesmo.

Assim, em uma das siderúrgicas, são percebidos aspectos relativos à cor e demais aspectos da fumaça que sai do forno (ora denominados de qualificadores). Essa percepção peculiar é essencial no controle do processo por parte dos operadores. Os atores da produção que compartilham desta mesma percepção e desta mesma linguagem são os operadores e os trabalhadores da área que lidam diretamente com as matérias-primas e com os produtos do forno siderúrgico. Os engenheiros de processo não percebem as mesmas características (parâmetros) da fumaça que os operadores e não conseguem estabelecer uma intercompreensão com estes, sobre os problemas do processo, no domínio de uma linguagem informal. Os dados foram registrados no Quadro 1. 
Quadro 1 - As percepções dos operadores e a linguagem compartilhada na atividade de trabalho

\begin{tabular}{|c|c|c|c|c|}
\hline Empresa & $\begin{array}{l}\text { Parâmetro } \\
\text { informal } \\
\text { percebido no } \\
\text { processo }\end{array}$ & $\begin{array}{c}\text { Alguns } \\
\text { qualificadores } \\
\text { detectados (na } \\
\text { linguagem) para o } \\
\text { parâmetro em } \\
\text { questão }\end{array}$ & $\begin{array}{c}\text { Atores que } \\
\text { compartilham } \\
\text { da mesma } \\
\text { percepção / } \\
\text { linguagem }\end{array}$ & $\begin{array}{c}\text { Atores que NÃO } \\
\text { compartilham da } \\
\text { mesma percepção / } \\
\text { linguagem dos } \\
\text { operadores }\end{array}$ \\
\hline Siderúrgica & $\begin{array}{l}\text { Cor e demais } \\
\text { aspectos da } \\
\text { fumaça que sai } \\
\text { do forno }\end{array}$ & $\begin{array}{l}\text { Clara, escura, } \\
\text { encorpada, rala, } \\
\text { grossa, fina, azulada, } \\
\text { esbranguiçada, } \\
\text { "preteada", alta, } \\
\text { baixa, leve, pesada, } \\
\text { etc. }\end{array}$ & $\begin{array}{l}\text { Operador de } \\
\text { processo } \\
\text { contínuo, } \\
\text { dangueiro, } \\
\text { lingoteiro, } \\
\text { forneiro }\end{array}$ & $\begin{array}{l}\text { Engenheiros, projetistas, } \\
\text { informáticos e gerentes } \\
\text { de processo }\end{array}$ \\
\hline $\begin{array}{l}\text { Fábrica de } \\
\text { cimento }\end{array}$ & $\begin{array}{l}\text { Distribuição do } \\
\text { produto sobre a } \\
\text { grelha }\end{array}$ & $\begin{array}{l}\text { Espalhado, } \\
\text { acumulado, formando } \\
\text { "boneco de neve", } \\
\text { formando "rio } \\
\text { vermelho", etc. }\end{array}$ & $\begin{array}{l}\text { Operador de } \\
\text { processo } \\
\text { contínuo, } \\
\text { forneiro, auxiliar } \\
\text { de produção } \\
\text { (área) }\end{array}$ & $\begin{array}{l}\text { Engenheiros, projetistas, } \\
\text { informáticos e gerentes } \\
\text { de processo }\end{array}$ \\
\hline $\begin{array}{l}\text { Fábrica de } \\
\text { cimento }\end{array}$ & $\begin{array}{l}\text { Poeira dentro } \\
\text { do forno }\end{array}$ & $\begin{array}{l}\text { Solta, presa, clara, } \\
\text { escura, alta, baixa, } \\
\text { "poeirinha", "poeirão", } \\
\text { etc. }\end{array}$ & $\begin{array}{l}\text { Operador de } \\
\text { processo } \\
\text { contínuo, } \\
\text { forneiro, auxiliar } \\
\text { de produção } \\
\text { (área) }\end{array}$ & $\begin{array}{l}\text { Engenheiros, projetistas, } \\
\text { informáticos e gerentes } \\
\text { de processo }\end{array}$ \\
\hline Siderúrgica & $\begin{array}{l}\text { Distribuição do } \\
\text { material em } \\
\text { torno do } \\
\text { eletrodo de } \\
\text { grafite }\end{array}$ & $\begin{array}{l}\text { Junto, afastado, } \\
\text { espalhado, } \\
\text { descoberto, vazado, } \\
\text { entupido, fechado, } \\
\text { aberto, etc. }\end{array}$ & $\begin{array}{l}\text { Operador de } \\
\text { processo } \\
\text { contínuo, } \\
\text { forneiro, auxiliar } \\
\text { de produção } \\
\text { (área) }\end{array}$ & $\begin{array}{l}\text { Engenheiros, projetistas, } \\
\text { informáticos e gerentes } \\
\text { de processo }\end{array}$ \\
\hline
\end{tabular}

$\mathrm{Na}$ fábrica de cimento, foram detectadas, na linguagem dos operadores, percepções peculiares sobre a distribuição do produto do forno sobre a grelha e sobre a poeira de dentro do forno. Existe uma câmera dentro do forno que fornece, ao operador, imagens da poeira no interior do reator de cimento. O controle do processo depende, em larga escala, de como o operador percebe os aspectos da poeira. Os trabalhadores utilizam-se de diferentes qualificadores para estabelecer um diálogo sobre o estado do processo. Esses qualificadores se referem às suas percepções sobre o estado do material e, indiretamente, sobre o estado do processo. Detectamos que estas percepções peculiares sobre as qualidades do material (qualificadores) não são compartilhadas pelos outros atores mais distantes da materialidade concreta do processo de produção (engenheiros e alguns supervisores). Os dados constam no Quadro 2. 
Quadro 2 - Agentes que compartilham de uma percepção comum e da intercompreensão na linguagem

\begin{tabular}{|c|c|c|c|c|}
\hline Empresa & $\begin{array}{l}\text { № de situações- } \\
\text { problema } \\
\text { investigadas } \\
\text { (Situações } \\
\text { dinâmicas) }\end{array}$ & $\begin{array}{l}\text { № de soluções } \\
\text { encontradas por } \\
\text { intermédio de } \\
\text { uma linguagem } \\
\text { informal } \\
\text { (culturalmente } \\
\text { situada) }\end{array}$ & $\begin{array}{l}\text { Atores que } \\
\text { compartilharam } \\
\text { da linguagem } \\
\text { informal e que } \\
\text { participaram da } \\
\text { solução do } \\
\text { problema }\end{array}$ & $\begin{array}{l}\text { Atores que permaneceram } \\
\text { alheios à linguagem } \\
\text { informal dos operadores }\end{array}$ \\
\hline Siderúrgicas & 19 & 18 & $\begin{array}{c}\text { Operadores e } \\
\text { pessoal de área }\end{array}$ & $\begin{array}{c}\text { Engenheiro de processo e } \\
\text { demais atores do domínio de } \\
\text { atuação } \\
\text { concepção/planejamento }\end{array}$ \\
\hline $\begin{array}{l}\text { Fábrica de } \\
\text { cimento }\end{array}$ & 28 & 27 & $\begin{array}{c}\text { Operadores e } \\
\text { pessoal de área }\end{array}$ & $\begin{array}{l}\text { Engenheiro de processo } \\
\text { e demais atores do domínio } \\
\text { de atuação } \\
\text { concepção/planejamento }\end{array}$ \\
\hline Petroquímica & 9 & 8 & $\begin{array}{c}\text { Operadores e } \\
\text { pessoal de área }\end{array}$ & $\begin{array}{c}\text { Engenheiro de processo } \\
\text { e demais atores do domínio } \\
\text { de atuação } \\
\text { concepção/planejamento }\end{array}$ \\
\hline
\end{tabular}

Há, no domínio concreto de atuação dos trabalhadores, em seu trabalho real, um saber tácito e incorporado que confere à produção o seu efetivo funcionamento dentro dos critérios de normalidade esperados. $O$ trabalho demanda a inteligência astuciosa, os instrumentos cognitivos (social e culturalmente situados) e as habilidades incorporadas para efetivar o controle do processo produtivo.

Nas situações reais, verifica-se um mosaico de diversos campos de saberes distintos que mobilizam os sistemas de produção, os quais podem ser encontrados, de fato, nas ações dos diferentes atores envolvidos nos diferentes domínios de produção.

Há, também, uma relação de cooperação entre concepção e execução, seja no domínio formal ou no informal mas, mesmo assim, os saberes operatórios, instalados nos recônditos da ação, inacessíveis aos demais domínios e demais observadores, permanecem nebulosos, sem a transparência de um registro simbólico formal, sem a legitimação por uma linguagem de intercâmbio entre diferentes domínios. Permanecem no escopo de uma "clandestinidade produtiva e eficiente".

Mesmo que as novas tecnologias de controle de processo tragam consigo o deslocamento das prescrições, de objetivos mais localizados operacionalmente, para objetivos mais amplos, e demandem atividades cognitivas e de planificação da ação aparentemente mais abstratas, ainda assim, é no nível mais elementar da 
atividade, cognitivamente incorporada e situada, atrelada às percepções, aos gestos e movimentos dos operadores, que se mantém instalada a capacidade de realizar um controle eficiente do processo. Conforme explicado anteriormente, trata-se de uma inteligência do corpo. É essa cognição situada, ligada a percepções e linguagem partilhadas por alguns atores, que mantém a produção em seu curso de normalidade. Nas atividades mais abstratas, que resultam em ações eficazes, verifica-se que os saberes tácitos, atrelados à história de experiências sensóriomotoras que perpassam o corpo (nos esquemas corporais ou incorporados e nas habilidades tácitas), permanecem como fundamentais a esses objetivos mais amplos.

Com toda a demanda de mobilização de saberes e subjetividades, o corpo e os saberes incorporados, os gestos e a sensório-motricidade (em sua íntima ligação com a percepção e a linguagem) permanecem como atributos indispensáveis às demandas mais sofisticadas dos modelos de produção contemporâneos.

Mesmo que haja um deslocamento para uma regulação coletiva do sistema de trabalho, as técnicas operatórias especializadas resguardam um domínio ontológico de saberes, percepções e habilidades que se materializam em atos indispensáveis ao bom funcionamento do sistema como um todo. A produção, que passa a ser fortemente influenciada pela regulação de equipes, mantém, ainda, a dependência dos estilos pessoais, das ações individuais, dos saberes, habilidades e percepções que cada indivíduo detém em seu corpo, em seus atos, em seus esquemas sensório-motores.

\section{CONSIDERAÇÕES FINAIS}

Os dados revelaram que os domínios de atuação distintos (operacional e gerencial) não dispõem de instrumentos linguísticos desenvolvidos de modo a gerar intercompreensão, reciprocidade de compreensão e compromisso mútuo na linguagem, com autenticidade.

Os operadores de processo contínuo, e os trabalhadores de área, compartilham de uma linguagem comum que é singular e bem diferente da linguagem dos responsáveis pela concepção, projeto e planejamento dos sistemas e 
do trabalho. Esta linguagem é resultado de uma vivência histórica num processo de produção específico. Ela não dispõe de formalização e não está legitimada epistemologicamente, não sendo sequer reconhecida pelos níveis hierárquicos superiores das empresas estudadas. No entanto, essa linguagem operacional funciona como instrumento cognitivo de eficiência no controle de processos de produção. Ela está atrelada a uma cognição situada cultural e socialmente, e a uma percepção que também resulta da experiência concreta (e corporal) da materialidade da produção. Ação, cognição e percepção andam juntas no contexto de incorporação ao processo produtivo.

A linguagem comporta duas dimensões: a dimensão da experiência vivida e a dimensão de simbolização (DERRIDA, 1967). Ou seja, a linguagem funciona como vivência de uma experiência e como simbolização desta experiência. Portanto, no caso da simbolização, só é possível como produto de uma vivência. Mas, quem o viveu? Quem o viveu não o pode simbolizar e não há, portanto, uma formalização que permita a compreensão dessa vivência das habilidades e dos saberes que, embora não simbolizados, efetivamente movimentam o real do trabalho (DEJOURS, 1997). Não há possibilidade de formalização integral de algo tácito e puramente vivenciado. Trata-se da parcela do real em que os dados vividos não podem ser completamente simbolizados, e a relação entre atos sensório-motores e atos abstratos da consciência é um tanto quanto complexa para se converter em descrição formal. Neste domínio tácito, mais que em qualquer outro, o real escapa a qualquer tentativa de simbolização ou recua, embora esteja repleto de dados que não se tornam visíveis e que ficam reclusos num mundo não simbolizado.

Por um lado, há um saber que possui sua natureza incorporada (tácita) na pura vivência corporal e mental. Por outro lado, não há um conjunto de códigos e símbolos tradicionalmente empregados na tradução desta parcela do real que emerge em situações específicas e, segundo Dejours (1997, p. 47), "resiste à simbolização", recua diante das tentativas de simbolização.

Surge no cenário da pesquisa, então, o intrincado terreno da subjetividade (CLOT, 1995), dado na relação do sujeito com seu trabalho e na relação social com outros atores situados num mesmo domínio de atuação. Nesta relação, ocorre a experiência íntima de situações de ação, nas quais são elaboradas soluções 
baseadas numa cognição incorporada. Ação e cognição se mantêm reclusas num mundo único, inacessível a uma relação objetivável com a linguagem. A ação operatória resguarda um terreno vertiginoso que aloja a profundidade do "eu" que se põe em serviço sem que ele mesmo o saiba conscientemente como; e sem que o possa explicar. Sua história, incorporada na forma de esquemas, está aí presente, em cada ato na ação, a se materializar na eficácia que escapa às prescrições e aos domínios de formalização.

Há, portanto, uma relação ao saber que não se torna completamente explícita ao próprio sujeito e, também, uma ausência de simbolização desta relação. Neste campo, a análise remete ao espaço da singularidade e da subjetividade de cada trabalhador, em sua relação com o saber corporificado, em seu mundo único de ação e compreensão.

O uso de habilidades tácitas ou incorporadas (DEJOURS, 1997, p. 40-46) aos atos do corpo anda junto de uma mobilização da subjetividade no seio do trabalho concreto da fábrica. Emergem daí essas habilidades que se prendem a um uso de si (SCHWARTZ, 1998) pelo sujeito em sua atividade. Esse campo não cabe nas prescrições e não pode ser inteiramente simbolizado, objetivado, formalizado. No efetivo funcionamento do trabalho concreto são, assim, mobilizados recursos de um recôndito domínio sensorial-cognitivo do sujeito atuante (e incorporado), os quais germinaram e floresceram ao longo de sua história no trabalho, em sua trajetória de vida: a história de aquisição de linguagem e habilidades não formalizáveis, que emergem aqui e ali na manutenção de um fluxo produtivo em aparente continuidade.

A experiência e a vida dos homens que trabalham não pode ser colocada entre parênteses, e são elas que animam a dimensão subjetiva da atividade num domínio inapreensível do agir operatório. Neste domínio, o agir excede o fazer: o agir guarda seus mistérios que permanecem indecifráveis, ainda que o fazer possa ser descrito objetivamente. 


\section{REFERÊNCIAS}

BATIONO TILLON, A., FOLCHER, V., RABARDEL, P. (2010). Les artefacts transitionnels: une proposition pour étudier la diachronie des activités narratives. Activités, v. 7, n. 2, pp. 63-83. Disponível em: < http://www.activites.org/v7n2/v7n2.pdf>.

BOUYER, Gilbert. A mente incorporada no controle de processo contínuo: ação, cognição e comunicação na atividade de trabalho. Gestão \& Produção, São Carlos, v.15, n.3, p. 539-550, dez. 2008.

BOUYER, Gilbert; SZNELWAR, Laerte. Enação e Processo de Trabalho: uma abordagem atuacionista da ação operatória. Gestão \& Produção, São Carlos, v.14, n.1, p. 97-108, abr. 2007.

CLOT, Yves. Le travail sans L'homme? pour une psychologie des milieux de travail et de vie. Paris: Éditions La Découverte, 1995.

CLOT, Yves. A função psicológica do trabalho. Petrópolis: Vozes, 2006.

DEJOURS, Christophe. O fator humano. Rio de Janeiro: FGV, 1997.

DEJOURS, Christophe. Conferências brasileiras: identidade, reconhecimento e transgressão no trabalho. São Paulo: Fundap Eaesp/FGV, 1999.

DERRIDA, Jaques. La voix et le phenomene. Paris: Presses Universitaires de France, 1967.

FOLCHER, V.; RABARDEL, P. Hommes, artefacts, activités: perspective instrumentale. In: FALZON, Pierre. (Org.). Ergonomie. Paris: Presses Universitaires de France, 2004, p. 251-268.

GUÉRIN, F. et al. Compreender o trabalho para transformá-lo: a prática da Ergonomia. São Paulo: Edgard Blücher, 2002.

HOC, J. M. La gestion de situation dynamique. In: FALZON, Pierre. (Org.).

Ergonomie. Paris: Presses Universitaires de France, 2004, p. 517-530.

HUBAULT, F. Do que a ergonomia pode fazer análise? In: DANIELLOU, F. (Org.). A ergonomia em busca de seus princípios: debates epistemológicos. São Paulo: Edgard Blücher, 2004, p. 105-140.

PASTRÉ, P. Genèse et identité. In: RABARDEL, P.; PASTRÉ, P. (Orgs.). Modèles du sujet pour la conception: dialectiques activités développement. Paris: Octarès: 2005, p. 231-260.

RABARDEL, P. Instrument subjectif et développement du povoir d'agir. In: 
RABARDEL, P.; PASTRÉ, P (Orgs.). Modèles du sujet pour la conception: dialectiques activités développement. Paris: Octarès: 2005, p. 11-29.

SCHWARTZ, Yves. Os Ingredientes da Competência: um Exercício Necessário para uma Questão Insolúvel. Educação \& Sociedade, Belo Horizonte, v.2, n.65, p.101139, dez. 1998.

THIBAULT, J. F. Contribuição da ergonomia em projetos de concepção e implantação de SDCD. In: DUARTE, F. (Org.). Ergonomia e projeto na indústria de processo contínuo. Rio de Janeiro: Lucerna, 2002, p. 173-186.

VERGNAUD, G. Schèmes et concepts dans une théorie opératoire de la représentation. Psychologie française, Paris, v. 3, n.30, p. 245-252, set. 1985

WISNER, A. Por dentro do trabalho: ergonomia, método e técnica. São Paulo: Oboré, 1987.

ZARIFIAN, P. Objéctif competence. Paris: Liaisons, 1999.

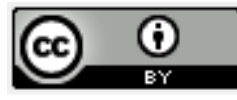

Artigo recebido em 29/09/2010 e aceito para publicação em 17/08/2011. 